\title{
Ocular health practices by dental surgeons in Southern Nigeria
}

\author{
Clement Chinedu Azodo ${ }^{1 *}$ and Ejike B Ezeja ${ }^{2}$
}

\begin{abstract}
Background: Dental professionals are among the occupational groups that experience ocular injuries and problems as they perform their daily dental works. The purpose of the study was to determine the ocular health practices by dental surgeons in Southern Nigeria.

Methods: This cross-sectional study was conducted on dental surgeons working in Southern Nigerian tertiary oral healthcare centers using self-developed validated questionnaire as the tool of data collection.

Results: Of the 148 respondents, 27 (18.2\%) rated their ocular health as poor/fair. More than half 82 (55.4\%) of the respondents have undergone professional eye examination with a quarter 20 (24.3\%) of them having received it, in the last 6 months. Symptomatic care was the major reason for the last visit. Medicated glasses use was found to be significantly associated with perception of ocular health and receipt of professional eye examination. A total of 32 (21.6\%) and 2 (1.4\%) of the respondents reported non-use of eye goggles and face mask respectively. Non-availability and associated visual clarity with goggle use were the main inhibitor to the regular safety eye goggles use among the respondents. The main suggested ways among the respondents of improving goggle use were training and provision of goggles free of charge for dental surgeons. Only 32 (21.6\%) of the respondents would be uncomfortable reminding their colleagues on need to use safety eye goggle while attending to patients.

Conclusion: Data from this study revealed that a significant proportion of the respondents rated the ocular health as excellent/good and do not regularly indulge in eye safety practices. Implementation of recommendation by the respondents may improve occupational eye safety among dental surgeons in Southern Nigeria.
\end{abstract}

Keywords: Professional eye examination, Safety eye goggle use, Self-rated ocular health, Dental surgeons, Dental procedures

\section{Background}

In adaptation of definition of health by World Health Organization (WHO), ocular health is considered as a complete state of physical, social and mental well-being in relation to vision and not necessarily the absence of disease and infirmity [1]. Ocular health is becoming an increasingly important issue in both the healthcare sector and society as a whole because undetected and untreated ocular conditions can lead to vision loss and blindness. The role of the eyes in mobility, function, and enjoyment of life underscore the importance of maintaining good ocular health. Vision disorders has been cited as the fourth most prevalent class of disability in

\footnotetext{
* Correspondence: clementazodo@yahoo.com

'Department of Periodontics, University of Benin, Benin City, Nigeria

Full list of author information is available at the end of the article
}

the United States [2] and the most prevalent handicapping conditions in childhood [3].

However, there are simple preventive and corrective measures to maintain good vision and consequent enjoyment of lifelong ocular health. These include wearing eye safety devices (safety glasses, protective goggles or face shields) while participating in sports or working with hazardous and airborne materials which lowers the risk of eye injury, damage to vision, and complete loss of sight. Visiting eye care professional for screening as early vision screening can lead to the detection, treatment, and prevention of many eye diseases. This is further illustrated by the fact that vision screening at well-child visits in medical homes significantly decreased the permanent visual loss due to amblyopia which is the medical

Ciomed Central

(c) 2014 Azodo and Ezeja; licensee BioMed Central Ltd. This is an Open Access article distributed under the terms of the Creative Commons Attribution License (http://creativecommons.org/licenses/by/4.0), which permits unrestricted use, distribution, and reproduction in any medium, provided the original work is properly credited. The Creative Commons Public Domain Dedication waiver (http://creativecommons.org/publicdomain/zero/1.0/) applies to the data made available in this article, unless otherwise stated. 
term used when vision in one eye is reduced because the eye and the brain are not working together properly [4].

The prevalence of ocular problems among Nigerian of different ages arising from aging, traumatic, genetic, nutritional, environmental and occupational agents qualify it as a significant overlooked health area [5-7]. Dental professionals are among the occupational groups that experience ocular injuries and problems as they perform their daily dental works [8]. Studies in Nigeria [9] and Saudi Arabia [10] have consistently reported high prevalence of conjunctivitis, work-related ocular injuries and infrequent eye protective device use in dental practice. Forty-three (43.0) percent of orthodontists in United Kingdom reported instances of ocular injury in their practices with majority of them occurring during debonding or trimming acrylic [11]. Seventy three percent of Greek endodontists reported ocular accidents with amalgam and $\mathrm{NaOCl}$ being the foreign bodies most frequently associated with them [12]. Self-reported ocular deterioration and impairment have also been reported in Nigerian Dental Surgeons [13]. There is therefore a need to determine the ocular health practices by dental surgeons in Southern Nigeria. Stokes et al. [14] in New Zealand recommended proper eye protective procedures in dental practices more than two decades ago because of the random nature of many eye injuries. Dental surgeons should be concerned about their ocular health and safety and are expected to protect their eyes with safety glasses, face shields or goggles which are designed to protect against work-related occupational injuries from projectiles, chemicals, dust, heat and biohazards. Despite the values and importance of eye protection, there have been documented evidences of poor eye safety practices in Nigeria $[15,16]$. The purpose of the study was to determine the ocular health practices by dental surgeons in Southern Nigeria.

\section{Methods}

This was a cross-sectional survey of 185 selected dental surgeons working in Oral Healthcare Centres of University Teaching Hospitals in Southern Nigeria. The criterion for selection was absence of self-reported chronic medical conditions. These Teaching Hospitals are actively involved in undergraduate and postgraduate training of dental workforce and have all cadres of dental surgeons in their employment. The hospitals include University College Hospital Ibadan; University of Benin Teaching Hospital, Benin City; University of Nigeria Teaching Hospital, Enugu; University of Port Harcourt Teaching Hospital, Port Harcourt; Lagos University Teaching Hospital, Idi-Araba and Obafemi Awolowo University, Ile-Ife. The research protocol was reviewed and approved by the College of Medical Sciences, University of Benin, Benin-City, Nigeria Research and Ethics
Committee. Informed consent was obtained from all the research participants. The survey was anonymous without identifiers. Participation was voluntary and no incentive was offered. A pretested self-administered questionnaire designed by the authors was used for data collection. The questionnaire was test and re-tested on ten dental surgeons working in private and secondary health facilities in Benin-City in a four week interval with reliability Cronbach's alpha of 0.85 . The questionnaire elicited information on demography (age, gender, years of practice experience, medicated glasses use, and average number of patient treated daily), perception of ocular health, reasons and timing of eye care visit, safety eye goggle and face mask use, barriers to regular use and ways to improve regular goggle use. Data obtained were subjected to descriptive statistics in form of frequencies, percentages and cross tabulations using Statistical Package for Social Sciences (SPSS) version 17.0. Chi square test was employed to check statistical significance. $\mathrm{P}<0.05$ was considered significant at $95 \%$ confidence interval. For the purpose of analysis the age of respondents was categorized as $\leq 30$ years and $>30$ years while and years of practice as $\leq 5$ years and $>5$ years.

\section{Results}

A total of 148 questionnaires were filled and returned, giving an overall response rate of $80.0 \%$ (148/185). Seventy nine respondents were less than 30 years old (53.4\%), 87 (58.8\%) were males, 110 had less or equal to 5 years practice experience $(74.3 \%)$ and 85 treated an average of $1-3$ patients per day (57.4\%). About one-third $47(31.8 \%)$ of the respondents use medicated glasses. The reason for medicated glasses use were myopia 30 (61.7\%), hyperopia 5 (10.6\%), astigmatism 12 (25.5\%) and photophobia 1 (2.1\%). A total of 27 (18.2\%) rated their ocular health as poor/fair while 121 (81.8\%) rated it as good/excellent. Perceived ocular health was not significantly associated with age, gender, years of practice and patient volume per day. However medication glasses use was significantly associated with perceived ocular health (Table 1). More than half $82(55.4 \%)$ of the respondents had undergone professional eye examination. This was not significantly associated with age, gender, years of practice and patient volume per day. However medication glasses use was significantly associated with professional eye examination (Table 2). Of the 82 respondents that had professional eye examination, 20 (24.3\%) had it in the last 6 months, 21 in the past 7-12 months (25.6\%), 9 in the past 13-24 months (11\%) and 32 more than 24 months ago (39\%).

Symptomatic care was the major reason for the last visit; routine check was the reason for ophthalmologic examination among 30 participants (36.6\%) (Table 3). Care received by the respondents that were mainly eye 
Table 1 Association between demographic/professional data of the participants and perceived ocular health

\begin{tabular}{|c|c|c|c|c|}
\hline \multirow[b]{3}{*}{ Characteristics } & \multicolumn{2}{|c|}{ Perception of ocular health } & \multirow[b]{2}{*}{$x^{2}$} & \multirow[b]{2}{*}{ P-value } \\
\hline & $\begin{array}{c}\text { Poor/fair } \\
\text { n (\%) }\end{array}$ & $\begin{array}{c}\text { Good/excellent } \\
n(\%)\end{array}$ & & \\
\hline & & & & \\
\hline Age (years) & & & 1.22 & 0.270 \\
\hline$\leq 30$ & $17(21.5)$ & $62(78.5)$ & & \\
\hline$>30$ & $10(14.5)$ & $59(85.5)$ & & \\
\hline Gender & & & 0.66 & 0.418 \\
\hline Male & $14(16.1)$ & $73(83.9)$ & & \\
\hline Female & $13(21.3)$ & $48(78.7)$ & & \\
\hline Year of practice & & & 0.27 & 0.603 \\
\hline$\leq 5$ & $19(17.3)$ & $91(82.7)$ & & \\
\hline$>5$ & $8(21.1)$ & $30(78.9)$ & & \\
\hline Medicated glasses use & & & 6.15 & $0.013^{*}$ \\
\hline Yes & $14(29.8)$ & $33(70.2)$ & & \\
\hline No & $13(12.9)$ & $88(87.1)$ & & \\
\hline Average number of patient treated per day & & & 0.05 & 0.827 \\
\hline $1-3$ & $15(17.6)$ & $70(82.4)$ & & \\
\hline$>3$ & $12(19.0)$ & $51(81.0)$ & & \\
\hline Total & $27(18.2)$ & $121(81.8)$ & & \\
\hline
\end{tabular}

$(*)=$ statistically significant.

Table 2 Associations between demographic/professional data of the participants and professional eye examination

\begin{tabular}{|c|c|c|c|c|}
\hline \multirow[b]{3}{*}{ Characteristics } & \multicolumn{2}{|c|}{ Eye check } & \multirow[b]{2}{*}{$x^{2}$} & \multirow[b]{2}{*}{ P-value } \\
\hline & $\begin{array}{c}\text { Yes } \\
\text { n (\%) }\end{array}$ & $\begin{array}{c}\text { No } \\
\text { n (\%) }\end{array}$ & & \\
\hline & & & & \\
\hline Age (years) & & & 0.84 & 0.358 \\
\hline$<30$ & $41(51.9)$ & $38(48.1)$ & & \\
\hline$>30$ & $41(59.4)$ & $28(40.6)$ & & \\
\hline Gender & & & 0.16 & 0.686 \\
\hline Male & $47(54.0)$ & $40(46.0)$ & & \\
\hline Female & $35(57.4)$ & $26(42.6)$ & & \\
\hline Year of practice & & & 2.23 & 0.135 \\
\hline$\leq 5$ & $57(51.8)$ & $53(48.2)$ & & \\
\hline$>5$ & $25(65.8)$ & $13(34.2)$ & & \\
\hline Medicated glasses use & & & 55.43 & $0.001^{*}$ \\
\hline Yes & $47(100.0)$ & $0(0.0)$ & & \\
\hline No & $35(34.7)$ & $66(65.3)$ & & \\
\hline Average number of patient treated per day & & & 0.49 & 0.484 \\
\hline $1-3$ & $45(52.9)$ & $40(47.1)$ & & \\
\hline$>3$ & $37(58.7)$ & $26(41.3)$ & & \\
\hline Total & $82(55.4)$ & $66(44.6)$ & & \\
\hline
\end{tabular}

$(*)=$ statistically significant. 
Table 3 Number $(\mathrm{N})$ and percentages (\%) of respondents in relation to the reasons for the last eye care visit

\begin{tabular}{lcc}
\hline Reason & Frequency $(\mathbf{n})$ & Percent (\%) \\
\hline Routine check & 30 & 36.6 \\
Difficulty in reading & 17 & 20.7 \\
Redness of eye & 10 & 12.2 \\
Pain & 9 & 11.0 \\
Itching & 5 & 6.1 \\
Glass repair & 2 & 2.4 \\
Double vision & 1 & 1.2 \\
Others & 8 & 9.8 \\
Total & 82 & 100.0 \\
\hline
\end{tabular}

glasses for non users $32(39.0 \%)$, eye drops $-16(19.5 \%)$ and change of eye glasses for users 13 (15.9\%) (Table 4). A total of $32(21.6 \%)$ and $2(1.4 \%)$ of the respondents reported non-use of eye goggles and face mask respectively (Table 5). Non availability [non provision of goggle by hospital authority $47(31.8 \%)$ and not having personal goggle $30(20.3 \%)$ ], and disturbance of vision clarity 27 (18.2\%) were the main inhibitors to the regular use of goggles. The main recommended ways by the respondents of improving goggle use were goggle provision at no cost $72(48.6 \%)$, training dentists on the importance of goggles in ocular safety $37(25.0 \%)$ and consideration of non-use as malpractice 20 (13.5\%) (Table 6). Only 32 (21.6\%) of the respondents would be uncomfortable reminding their colleagues on the need to use goggle while attending to patients. None and irregular eye protector wearers reported more poor/fair perceived ocular health than regular eye protector wearers and this was statistically significant. The reason for eye care visit was not statistically associated with perceived ocular health (Table 7).

\section{Discussion}

The perception of ocular health which was modeled from the global oral and general health rating is expected to permit individuals to subjectively describe their health

Table 4 Eye care services received by the respondents

\begin{tabular}{lcc}
\hline Care & $\begin{array}{c}\text { Frequency } \\
\text { N }\end{array}$ & $\begin{array}{c}\text { Percent } \\
\%\end{array}$ \\
\hline Eye glasses & 32 & 39.0 \\
Eye drops & 16 & 19.5 \\
Change of eye glasses & 13 & 15.9 \\
Tablets/or capsules & 4 & 4.9 \\
Eye surgery & 2 & 2.4 \\
Unspecified & 15 & 18.3 \\
Total & 82 & 100.0 \\
\hline
\end{tabular}

Table $\mathbf{5}$ The frequency of utilization of eye protector and face mask among the respondents

\begin{tabular}{lcc}
\hline & \multicolumn{2}{c}{ Facial Barrier use } \\
\cline { 2 - 3 } Pattern of use & Eye protector $\mathbf{n}(\%)$ & Face mask $\mathbf{n}(\%)$ \\
\hline Never & $32(21.6)$ & $2(1.4)$ \\
Irregular & $66(44.6)$ & $8(5.4)$ \\
Regular & $50(33.8)$ & $138(93.2)$ \\
Total & $148(100.0)$ & $148(100.0)$ \\
\hline
\end{tabular}

in epidemiological study. In this study, about one-fifth $(19.3 \%)$ of the respondents rated their ocular health as fair/poor. The reasonable proportion of respondents with this rating implies this, as a health issue of concern. This indicates that assessment of clinical indicators of the poor ocular perception through ophthalmological examination may be necessary.

Vision problems constitute a substantial burden on the affected individuals, their caregivers, healthcare payers, and the national economy. Although regular comprehensive eye examinations are essential for prevention and timely treatment of eye disease to maintain ocular health, a previous study has shown that substantial percentages of persons do not seek eye care services, despite having visual impairment [2]. The perfidious onset of vision changes has led to the recommendation that all dentists should undergo eyesight testing at intervals of 2 years until the age of 50, and more frequently thereafter [17]. This is in accordance with that of the sight test intervals recommended by the Association of Optometrists (2006) [18] for the general population. It is well recognized that good eyesight is important for the practice of dentistry but it is apparent that regular eye testing are not undertaking by dentists [19]. In this study, more than half $(55.7 \%)$ of the respondents had professional eye examination and $50 \%$ of them had it, in the last 12 months. This signifies that professional ocular examination was not a major health seeking behaviour by the respondents and portends that the recommended annual eye check-up was not well imbibed. This nonadherence to the recommended annual eye check-up has also been reported among doctors in Lagos, Nigeria but the prevalence of professional eye examination $(86.0 \%)$ [20] was higher than the reported value in this study. Chadwick et al. [19] reported that only $16.0 \%$ of dentists in United Kingdom failed to seek routine eye examination at least every two years. A total of $36.6 \%$ of the respondents attended for the eye professional check in this study which is lower than the 57\% reported in Scotland [21] and the 54\% reported amongst Greek endodontists [12]. This may imply that dentists in developing countries are less concerned about their ocular health than dentists in developed countries. The symptomatic 
Table 6 The recommended ways to improve goggle use among the respondents

\begin{tabular}{lcc}
\hline Ways & Frequency & Percent \\
\hline Provision of goggle at no cost & 72 & 48.7 \\
Training dentists on the importance of goggle in ocular safety & 37 & 25.0 \\
Consideration of non-use as malpractice & 20 & 13.5 \\
Monitor of goggle use by hospital authority & 16 & 10.8 \\
Unspecified & 3 & 2.0 \\
Total & 148 & 100.0 \\
\hline
\end{tabular}

care was the major reason for the last visit in this study signifying that the regular eye examinations should be encouraged. This form of eye care visit explained the pattern of care received by the respondents which were eye glasses prescription, eye surgeries and medications in form of tablets, capsules and eye drops.

In this study, about one-third (31.8\%) of the respondents use medicated glasses which is comparable to $36.1 \%$ reported among dental surgeons attending continuing education course in Nigeria [13]. The medicated glasses use is significantly associated with the prevalence of eye care visit and perception of ocular health. This tallied with the findings among dentists in the United Kingdom with known eyesight deficiencies attending for more routine eye examination than their counterparts [19]. Also dental students who had their eyesight corrected were significantly more likely to attend for examination biennially than those without correction [22]. The higher poor/fair ocular health rating among medicated glass users may not be unconnected with the psychology of prosthesis to augment the physiological function of organs or tissues of the body. This is confirmed by the report of a previous study which stated that wearing eyeglasses can negatively affect physical self-esteem [23]. Similarly wearing oral prosthesis in form of removable denture resulted in poor self-rated oral health [24].

Eye safety device use in form of safety glasses and protective goggles while working protects against foreign bodies, splashes, aerosols, curing light, projectiles, chemicals, dust, heat and biohazards thereby lowering the risk for eye injury and damage to vision. Eye safety practices are included in the Guidelines for Infection Control in Dental Health-Care Setting 2003. The adoption of protective eyewear has been found to patchy thereby exposing dentists to unnecessary risk [19]. Although eye protection are categorized into adequate and inadequate with adequate eye protection including prescription glasses with side shields, face shields, safety glasses and magnifying loupes and inadequate eye protection including prescription glasses without side shields and without adequate frame diameter [25]. However protective eye wear in this study was categorized into regular, irregular and none use as previously used eye safety practices studies among dental healthcare providers in Nigeria. In this study, protective eye wear was regular (33.8\%) and irregular (44.6\%) among the respondents. It was also found that $21.6 \%$ of the respondents never used safety eye goggle. The relative higher regular use of face mask than eye goggle [93.2\% versus $33.8 \%$ ] reflects the non-availability and associated discomfort with eye goggle use. The highly visual demanding work performed by dentists requires safety glasses that are not yet available on the market, which might also explain the none and irregular use [26]. Irregular eye protector wearers reported statistically more poor/fair perceived ocular health than regular eye protector wearers explaining that preventive health behaviour results in better health. The predominantly cited barrier to safety eye goggle use were non-availability and disturbance of vision clarity. The fact that non-availability and disturbance of vision were the predominant reasons for non goggle use explained why respondents recommended training and provision of goggles free of charge as the main ways of

Table 7 Association between perceived ocular health, eye protector wear and reason for eye care visit

\begin{tabular}{|c|c|c|c|c|c|}
\hline \multirow[b]{2}{*}{ Variable } & \multicolumn{2}{|c|}{ Perception of ocular health } & \multirow[b]{2}{*}{ Total n (\%) } & \multirow[b]{2}{*}{$x^{2}$} & \multirow[b]{2}{*}{ P-value } \\
\hline & Poor/fair n (\%) & Excellent/good $\mathrm{n}(\%)$ & & & \\
\hline \multicolumn{6}{|c|}{ Eye protector wear } \\
\hline Never & $15(46.9)$ & $17(53.1)$ & $32(100.0)$ & 22.447 & $0.000^{*}$ \\
\hline Irregular & $7(10.6)$ & $59(89.4)$ & $66(100.0)$ & & \\
\hline Regular & $5(10.0)$ & $45(90.0)$ & $50(100.0)$ & & \\
\hline \multicolumn{6}{|c|}{ Reason for eye care visit } \\
\hline Symptomatic & $10(19.2)$ & $42(80.8)$ & $52(100.0)$ & 0.084 & 0.772 \\
\hline Preventive & $5(20.0)$ & $25(20.0)$ & $30(100.0)$ & & \\
\hline
\end{tabular}

$(*)=$ statistically significant. 
improving safety eye goggle use. It was also revealed from this study that peer model may facilitate improvement in the use of goggle as $78.4 \%$ of the respondents would be comfortable reminding their colleagues on the need to use goggle while attending to patients. It has been shown that improvement in the utilization of eye care services occurred among Australians who were not aware of eye health and needed routine eye examinations after health promotion by primary care providers [27]. Dentists therefore should be encouraged to be actively involved in their ocular health in collaboration with eye care professional inorder to increase their chances for achieving and maintaining good ocular health.

\section{Conclusion}

Data from this study revealed that a significant proportion of the respondents rated the health of their eyes as excellent/good. The symptomatic care was the major reason for professional eyecare visit and appreciable proportion of the respondents does not regularly indulge in eye safety practices. Implementation of recommendation of the respondents would improve occupational eye safety practices among dental surgeons in southern Nigeria.

\section{Competing interest}

The authors declare that they have no competing interests.

\section{Authors' contributions}

CCA conceived the study made substantial contributions to design and literature review, involved in drafting the manuscript and approved final version to be published. EBE made substantial contributions to design and acquisition of data, involved in drafting the manuscript and approved final version to be published. Both authors read and approved the final manuscript.

\section{Authors' information}

CCA holds Bachelor of Dental Surgery (BDS) Degree, Master of Physiology (MSc Physio.) degree, Master of Public Health (MPH) degree and Fellowship of National Postgraduate College of Nigeria (FMCDS) lectures Periodontology in University of Benin and practices as a Consultant Periodontology at the University of Benin Teaching Hospital Benin City, Nigeria.

EBE holds Bachelor of Dental Surgery (BDS) Degree and is currently a DDS students of Minnesota Dental School, United States of America.

\section{Acknowledgement}

This study was conducted as out of pocket expenses and no external funding was received. The authors are grateful to the Dr. Odai of Department of Oral Surgery and Oral Pathology, University of Benin for his constructive criticism that improved the quality of this manuscript.

\section{Author details}

'Department of Periodontics, University of Benin, Benin City, Nigeria. 2Department of Preventive Dentistry, University of Benin Teaching Hospital, Benin City, Nigeria.

Received: 22 April 2014 Accepted: 9 September 2014

Published: 11 September 2014

\section{References}

1. Official Records of the World Health Organization: Preamble to the Constitution of the World Health Organization as adopted by the International Health Conference, New York, 19-22 June, 1946; signed on 22 July 1946 by the representatives of 61 States.; 1948:2-100. and entered into force on 7 April.
2. Lee DJ, Lam BL, Arora S, Arheart KL, McCollister KE, Zheng DD, Christ SL, Davila EP: Reported eye care utilization and health insurance status among US adults. Arch Ophthalmol 2009, 127(3):303-310.

3. Adhikari S, Paudel N, Adhikari P, Shrestha GS, Shrestha JB: Screening preschool children for visual disorders: A pilot study. Optom Vis Perf 2013, 1(6):202-207.

4. Centers for Disease Control and Prevention (CDC): Vision health initiative: Common eye disorders. Atlanta, GA: Author;; 2013. Online at: http://www.cdc.gov/ visionhealth/basic_information/eye_disorders.htm Accessed 01/07/2013.

5. Kragha IK: Eye diseases in northern Nigeria: prevalence, age and sex differences. Ophthalmic Physiol Opt 1987, 7(4):481-483.

6. Nwosu SN: Blindness and visual impairment in Anambra State. Nigeria Trop Geogr Med 1994, 46(6):346-349.

7. Babalola OE: The peculiar challenges of blindness prevention in Nigeria: a review article. Afr J Med Med Sci 2011, 40(4):309-319.

8. Kihara T: Dental care works and work-related complaints of dentists. Kurume Med J 1995, 42(4):251-257.

9. Ajayi YO, Ajayi EO: Prevalence of ocular injury and the use of protective eye wear among the dental personnel in a teaching hospital. Nig Q J Hosp Med 2008, 18(2):83-86.

10. Al Wazzan KA, Almas K, Al Qahtani MQ, Al Shethri SE, Khan N: Prevalence of ocular injuries, conjunctivitis and use of eye protection among dental personnel in Riyadh, Saudi Arabia. Int Dent J 2001, 51(2):89-94.

11. Sims AP, Roberts-Harry TJ, Roberts-Harry DP: The incidence and prevention of ocular injuries in orthodontic practice. Br J Orthod 1993, 20(4):339-343.

12. Zarra T, Lambrianidis T: Occupational ocular accidents amongst Greek endodontists: a national questionnaire survey. Int Endod J 2013, 46(8):710-719.

13. Oboro HO, Azodo CC, Ehizele AO, Sede MA, Chukwumah NM: Perceived visual deterioration among a selected group of dental surgeons in Nigeria. Nig Med Pract 2011, 59(1-2):24-30.

14. Stokes AN, Burton JF, Beale RR: Eye protection in dental practice. N Z Dent J 1990, 86(383):14-15.

15. Sofola OO, Savage KO: Assessment of the compliance of Nigerian dentists with infection control: a preliminary study. Infect Control Hosp Epidemiol 2003, 24(10):737-740.

16. Utomi IL: Attitudes of Nigerian dentists towards hepatitis B vaccination and use of barrier techniques. West Afr J Med 2005, 24(3):223-226.

17. Gilbert JA: The dentist and the ageing eye. J Mo Dent Assoc 1980, 74:22-24.

18. Association of Optometrists: General Opthalmic services and optical voucher scheme. Making accurate clains in Scotland. http://www.aop.org.uk/uploads/ uploaded_files/GOS/GOS\%20\&\%20Regulatory/GOS/Scotland/ mac_2012_compressed.pdf.

19. Chadwick RG, Alatsaris M, Ranka M: Eye care habits of dentists registered in the United Kingdom. Br Dent J 2007, 203(4):E7.

20. Akinsola FB, Alimi HL, Oyeleye TO, Majekodunmi AA: Knowledge, attitude and practice of eye health care amongst doctors in Lagos. Nig Q J Hosp Med 2004, 14(1):31-34.

21. Forgie AH, Gearie T, Pine CM, Pitts NB: Visual standards in a sample of dentists working within Scotland. Prim Dent Care 2001, 8(3):124-127.

22. Chadwick RG: Factors influencing dental students to attend for eye examination. J Oral Rehabil 1999, 26(1):72-74.

23. Jellesmaa FC: Do glasses change children's perceptions? Effects of eyeglasses on peer- and self-perception. Euro J Dev Psychol 2013, 10(4):449-460

24. Jones JA, Orner MB, Spiro A 3rd, Kressin NR: Tooth loss and dentures: patients' perspectives. Int Dent J 2003, 53(5 Suppl):327-334.

25. British Dental Association: Infection Control in Dentistry, BDA Advice Sheet A12. London: BDA; 2009. http://www.suffolkextranet.nhs.uk/LinkClick.aspx? fileticket=mlzoywbCtTE\%3D\&tabid=1314\&mid=2604.

26. Lönnroth EC, Shahnavaz H: Users' demands regarding dental safety glasses. Combining a quantitative approach and grounded theory for the data analysis. Int $J$ Occup Saf Ergon 2001, 7(1):49-59.

27. Müller A, Keeffe JE, Taylor HR: Changes in eye care utilization following an eye health promotion campaign. Clin Experiment Ophthalmol 2007, 35(4):305-309.

doi:10.1186/1472-6831-14-115

Cite this article as: Azodo and Ezeja: Ocular health practices by dental surgeons in Southern Nigeria. BMC Oral Health 2014 14:115. 